\title{
CLIENT-CENTERED THERAPY IN JAPAN
}

\author{
FUJIO TOMODA
}

\author{
Kokugakuin University
}

What is non-directive counseling? or client-centered therapy? It is very difficult to give a definite or objective answer to this question, though this is the focus issue of this point of view. Strictly speaking, I should like to say that no one knows at present the actual maning of these terms. I have been impressed that there are various kinds of so-called non-directive counselors or client-centered therapists, not only in Japan, but also in America, and that the diversity of the meaning of these terms has been increasing more and more with the progress of clinical works. But I will not discuss further the meaning of these terms in this paper, rather I will use these terms to indicate the thought and clinical methods which were created by Carl R. Rogers and developed both by him and by his colleagues in the United States.

First, I will describe a brief history of the development of this point of view in Japan, as objectively as I can. Secondly I will review the research works which have been conducted in connection with this procedure.

Counseling and psychotherapy are flelds which have been often criticized as to their scientific exactness. It is true, at least, in the case of non-directive or client-centered. And it is also true that the scientific research about this procedure in Japan has left much to be done.

\section{DEVELOPMENT OF THE CLIENT-CENTERED POINT OF VIEW IN JAPAN.}

It was in 1947 that the writer had a chance to know the so-called non-directive or client-centered viewpoint through Rogan J. Fox, ${ }^{*}$ one of the former students of Rogers. I was the chief of the Counseling Center of Tokyo University of Letters and Science** at that time and had been worrying very much about my clinical failures in the so-called directive procedure. As I had much interest in the Rogers' point of view, I borrowed his first book, "Counseling and psychotherapy - I 942 " from Fox and I began to devote myself to the clinical investigations of the effect of this approach. Experimenting with Rogers' method on my clients for a few years, I came to believe firmly that this method would be also successful in Japan.

On the other hand, Masashi Masaki, then Professor of Tohoku University, could learn Rogers' principle from Arthur T. Jersild, who came to Japan as a lecturer of the IFEL (Institute for Educational Leaders) in 1948 . He showed much interest in this principle as an educational psychologist. He began to introduce the non-directive or clientcentered point of view to the educational field and to devote himself to find out the theoretical possibilities of this introduction.

The Institutes for Student Personnel Services, which were held in 1951 - I 952 at Kyoto, Kyushu and Tokyo Universities (3), and in the summer of 1955 in Tokyo University under the leadership of Wesley P. Lloyd of Brigham Young University, introduced the non-directive counseling to student counselors in whole Japan, with demonstrations of the procedure by role playing. At the first Institute Chester $\mathrm{H}$. Ruedisili of the University of $W$ isconsin and Henry Borow of the University of Minnesota joined the staff as psychologists, and stayed in Japan for one year. In the summer institute of 1955 (advanced course), Francis P. Robinson of Ohio State University and Edward S. Bordin of the University of Michigan, who belong to the highest authorities in American counseling psychology, worked as advisors with Lloyd. Bordin returned to Japan in 1957

\footnotetext{
* He is now the President of Ibaraki Christian College in Japan.

** This University is now called the Tokyo University of Education.
} 
and stayed during the spring semester in Kyoto University as a lecturer at the American Studies Seminar. He contributed much for the deeper understanding of characteristics of the non-directive counseling with the background of psychoanalysis and other former directive methods.

At the end of $\mathrm{r} 95 \mathrm{I}$, the writer published a Japanese translation of the Rogers' first book, "Counseling and psychotherapy," and then published in $1952 \mathrm{my}$ book, "Techniques of interview in guidance" (7) with my own clinical materials. Masaki expressed the theoretical possibilities of his introduction of this point of view into educational area in his book, "The educational man" (4) in 1953.

In I 955, the writer had the first workshop on the non-directive viewpoint at Ibaraki Christian College for ten days, in cooperation with Fox and Tsutomu Endo of Ibaraki Child Guidance Center, who had made remarkable progress as a non-directive counselor in contact with Fox and the writer. Most participants of this workshop had realized the effect of this procedure so much that they wished enthusiastically to continue their studies on counseling together. They established the Tokyo Counseling Center*** in December of this year and the writer was elected the director of the Center.

Meanwhile, the writer published the Japanese translation of the Rogers' second book, "Client-centered therapy-1951" in three volumes from 1955 to I956, and published my second book, "Techniques of counseling from the client-centered point of view," (8) in 1956 . These books have stimulated the progress of this approach in Japan together with the influence of National Institute of Mental Health. Tsuneo Imura, the former chief of the Psychological Department of the Institute, was interested in this method and influenced Morio Saji, some other members of the staff, and the staff of Edogawa Institute for Educational Research. They had been working with their clients from the so-called non-directive or client-centered point of view, independently from the writer, and getting the same success with their clients. In 1956 , they became the leading members of the Tokyo Counseling Center and the writer became a consultant of Edogawa Institute.

In the spring of 1956 , Koji Sato of Kyoto University visited Rogers at his Counseling Center in Chicago and discussed with him about the relationship of his way of thinking with Oriental modes of thought. Sato told him about Zen and Morita Therapy; though he went to China when he was young, Rogers was not yet familiar with these Oriental thoughts.

In 1957, the writer published the Japanese translation of the Rogers' third book, "Psychotherapy and personality change-1954." This was a joint work of the seven members of the Tokyo Counseling Center. And in 1958, Fox and Endo published a book, "Counseling and problem children" (2). This is the first case-book of non-directive counseling of the so-called juvenile delinquents and the adolescents with criminal bent in Japan.

Today, the Tokyo Counseling Center has seven branches in Japan and it has about 200 members all over Japan. In 1957, the writer could visit the United States, and stayed at the Counseling Center of the University of Chicago for five months, and visited Rogers at the University of Wisconsin. Coming back from America at the end of last February, the writer has been impressed more and more keenly that in Japan the

***The address of the Center is: 48,3 chome, Nishigahara, Kita-ku, Tokyo, Japan. 
Rogers' point of view has been spreading widely and rapidly in various areas; i.e., not only the professional clinical area, but also in the social work, in the industrial personnel work, in the treatment of prisoners, etc.

\section{PROGRESS IN RESEARCH.}

In spite of the rapid progress and the wide spreading of this point of view in practice, the progress in research on this theory and method seems to be not so remarkable. It is due to the characteristics of counseling or psychotherapy itself, as I have mentioned above. In spite of the fact, there are not a few research works on this approach, of which three representative ones will be reported.

The first one is Endo's study on the effect of non-directive method in I955 (I). Fifty juvenile delinquents were sent to his office by the institution from the beginning of the year to the end of August of r 955. He worked with them with the Rogers' method, while they were kept in Ibaraki Child Guidance Center temporarily. The ages of the delinquents ranged from 8 to 17 ; and the I.Q. from 63 to 1 I5. The effect of his counseling was evaluated in the case conference in the Center which consisted of psychiatrists, psychologists, case-workers and some other staff who had some relations with the delinquents. According to their evaluation, the effect of Endo's non-directive counseling was summarized as follows; 33 delinquents $(66 \%)$ had achieved their personality change very successfully and others were rather unsuccessful. Eight of the thirty-three, who were very successful, had more than io session with the counselor and all of them had achieved their success completely (roo\%), but the rate of success decreased in the delinquents who had less than ro sessions; 6 to 8 sessions $77 \%$; and 4 to 5 sessions, $44 \%$. The counselor worked successfully with the delinquents who were older than 12 years old (the rate of success was $75 \%$ ), but rather unsuccessful with the ones who were younger than I I years old (43\%). The counseling was very successful with the ones whose I. Q. were more than $75(75 \%)$, but rather unsuccessful, when less than $74(50 \%)$.

The effect of Endo's counseling may seem too marvellous to some readers. But I am sure there was no mistake in this evaluation which was made carefully by the staff of the Center. I had one question on this point; whether the effect was due to his counseling, or the therapeutic treatment and the therapeutic atmosphere in this Center? Endo wrote his answer that he had estimated highly the other factors besides his counseling.

The second study was made by the writer in 1956 (9). The writer had worked with a client who had been diagnosed as the heart-neurosis by two physicians. As a client-centered therapist, I had 15 sessions with him and got completely the verbatim records of every session with the electoric recorder. And then, I classified all of the client's statements in the counseling situation into four categories, which C. A. Curran mentioned in his book, "Personality factors in counseling - r 949 ." When I classified the client's statements into categories, I worked with one psychologist. The findings of this study were as follows :

I) The process is not smooth but irregular in general.

2) The negative and the positive emotional statements of the client show positive correlation through the process and both of them decrease at the end of it.

3) The statements of insight have the negative correlation with the negative emotional statements and the latter usually precedes the former. 
4) At the beginning of the process, the emotional statements are dominant, but they decrease at the end of it and the statements of choice and insight become rather dominant.

5) Generally speaking, the total process of this counseling has much similarity with the one which was decribed in the Curran's book.

There remains one important question in my mind; that is the one mentioned in 3). The negative emotional statements are usually taken to be one of the important symptoms of maladjustment or neurosis. But, is it the only functional meaning or the only role of negative emotional statements? Can they have something to indicate the personality change or development in themselves?

The most intensive research on the client-centered method has been progressing in National Institute of Mental Health. The research in the Institute is not merely the study on the client-centered procedure, but on psychotherapy in general. But I have been strongly impressed that the researchers have been influenced intensively from Rogers and his colleagues, and that they have come to justify the validity of psychotherapeutic principles of Rogers' method, as they mentioned in their report.

In I 956, Morio Saji and Yasufumi Kataguchi, who belong to the psychological Department of the Institute, published a report of their joint research, "A study on the measurement of the effect of psychotherapy," in the Joural of Mental Health, the bulletin of the Institute (6). They made their research in order to find out the regularity in the course of psychotherapy, by means of measuring the effect of treatment and evaluating the process of the therapy. They used the verbatim records of five clients who had come to get help at the Institute. They prepared the five categorical criteria with the intention of seeking changes in the client's attitudes affected by the therapy;

(I) Degree of the development of symptom and the client's attitude towards the symtom.

(2) Degree of the emotional maturity as well as the conduct adaptability.

(3) Extent of the harmony of inter-personal relationship.

(4) The client's attitude toward the therapy.

(5) The level of insight.

They prepared the movement scales which included the five values for each categories and four judges evaluated the statements of five clients independently at the beginning and the end of therapy. They used the Rorschach Test to each client before and after their thrapeutic contacts in order to assess the effect of the therapy.

They prepared another category of 47 criteria selected for the use of the quantitative analysis of the verbalized contents and five aspects in analyzing the clients' attitudes. In the former analysis, the three judges were asked to choose the categories independently and the four judges were asked to analyze the clients' attitudes. The five aspects which were prepared in analyzing the clients' attitudes were as follows: (a) client's independent estimation, (b) acceptance of himself, (c) acceptance of other persons, (d) adjustment to the life situation, (e) his defensive attitude.

They prepared three aspects of therapist-client inter-relationship to carry out the analysis with which they would find out the regularity between the therapist-client relationship and the development of the client.

Though I cannot introduce this study in detail for the lack of space, 1 can summarize the result and say that the researches expressed their agreement with the Rogers' view in general. 


\section{SOME CRITICISMS ON THE ROGERS' POINT OF VIEW}

In spite of (or, because of) the rapid progress and the wide spread of the Rogers' point of view in Japan, we must not ignore the criticisms to this approach. The most criticisms have been also introduced from America: there are many mysterious aspects in this approach; it is not a science, but a religion, because of the lack of diagnosis and case history; it has no or very poor theoretical system as a scientific procedure, in spite of its practical success; etc. But there are also some unique criticisms in this country: the basic assumption of Rogers is not different from that of Mencius, a wise man in ancient China, who expressed the view of human nature as fundamentally good; the non-directive or the client-centered way of thinking is same with those of Morita therapy which was created by the late Shoma Morita, a Japanese psychiatrist; etc. Really, we can find out the basic assumptions of Rogers in the Discourses of Mencius and in the therapeutic theory of Dr. Morita. And sometimes, we have heard some criticisms to this point of view from the standpoint of Buddhism, especially Zen-Buddhism.

It would be true that many Japanese psychologists, especially psychiatrists, would have been unable to accept the Rogers' point of view, chiefly because of the lack of experience in non-directive therapy.

\section{SUMMARY}

This paper aims to introduce the curreat situation of the so-called non-directive or client-centered point of view in Japan. Since this method was introduced to Japan in 1947-1948, it has been making a rapid progress and spreading widely in various fields. The Institutes for Student Personnel Services, Tokyo Counseling Center, National Institute of Mental Health and the translations of Rogers' works by the writer have contributed much to promote such tendency in Japan. The scientific research on this stand point in Japan is not so well-known, due to the difficulties of research on psychotherapeutic process. Three representative studies were reviewed. There are not a few criticisms to Rogers' thought and methods from Japanese viewpoints.

\section{BIBLIOGRAPHY}

I. Endo, T. The effect of client-centered counseling with juvenile delinquents. Proc. of Jap. Assoc. appl. Psychol., 1955, 20, 39.

2. Fox, R. J., \& Endo, T. Counseling and problem children. Tokyo: Iwasaki Shoten, 1958.

3. Lloyd, W. P. Student counseling in Japan. Minneapolis : Univer. of Minnesota Press, 1953.

4. Masaki, M. Educational man. Tokyo: Dogakusha, 1953.

5. Saji, M. A case treated by non-directive method, $J$. Mental Health, x957, 5, 7-62.

6. Saji, M., $\&$ Kataguchi, Y. A study on the measurement of the effect of psychotherapy. J. Mental Health, 1956, 4, 65-112.

7. Tomoda, F. Techniques of intervied in guidance. Tokyo: Kaneko Shobo, 1952.

8. Tomoda, F. Techniques of counseling from the client-centered point of view. Tokyo: Seishin Shobo, 1956.

9. Tomoda, F. An analytical study of client-centered therapeutic process. Proc. Jap. Ass. appl. Psychol., $1957,23,40-42$.

Fujio Tomoda (友田不二男 1917- ) Graduated from Tokyo Bunrika University in 194I. I948- Assistant, Tokyo Bunrika University; I950- Assistant Professor of Clinical Psychology, Kokugakuin University. 